\title{
DESIGN AND FABRICATION OF PANTOGRAPH MECHANISM
}

\author{
J. THAMILARASAN ${ }^{1}$, A. PRABHU ${ }^{2}$, R. PUSHAPKUMAR ${ }^{3} \&$ K. KARTHIK ${ }^{4}$ \\ ${ }^{1,2,4}$ Assistant professor, Department of Mechanical Engineering, Veltech Dr \\ RR \& Dr. SR University, Avadi, Chennai, Tamil Nadu, India \\ ${ }^{3}$ Assistant Professor, Department of Information technology Engineering, Veltech, Dr. \\ RR \& Dr. SR University, Avadi, Chennai, Tamil Nadu, India
}

\begin{abstract}
One of the major problem during sheet metal working is cutting of large and complex shapes on the sheet metal. This is due to errors and involvement of large process and equipment's in drawing those shapes, like drawing a circle with big diameter is very difficult (Range of compass is $300 \mathrm{~mm}$ diameter). Drawing a complex shape on sheet metal needs a scale, protector, compass, drafter etc., and for some shapes like parabola and ellipse, we do not have the equipment to draw. But a similar shape on a smaller scale is easier to draw in software like AutoCAD and solid works and can easily take print out for the smaller scale. If the same drawing can be magnified, the difficulty in drawing the complex shapes on sheet metal can be minimized. Therefore, this project is aimed at developing a Pantograph mechanism, which can be used to magnify the smaller shapes on the sheet metals. And it replaces all the drawing tools on the work table. Another use of this mechanism is a single reference drawing is enough to draw a similar magnified drawing on many sheet metals.

KEYWORDS: Pantograph Mechanism, Work Table, Compass \& Sheet Metal Working
\end{abstract}

Received: Jan 02, 2018; Accepted: Jan 22, 2018; Published: Mar 19, 2018; Paper Id.: IJMPERDAPR2018110

\section{INTRODUCTION}

The pantograph is one of the fascinating pieces of engineering equipment ever invented and in some form or other; it should be part of every engineering shop's equipment. Engraving lines in two dimensions are just one of its functions, more sophisticated versions work in two dimensions and will copy complicated two-dimensional designs and engineered components, enlarging or reducing them in size as required. A pantograph is a simple yet powerful tool, which can broaden the scope of artwork and crafting.

We can enlarge or reduce images with a pantograph depending on how the parts are measured and assembled. The pantograph calculates the distances between its pivot points and resizes the image as the "algorithm" for creating the final copy. The pantograph in the illustration would produce a copy smaller than the original. The percentage of enlargement of the pantograph was provided by changing the distances between the pivot points.

In engineering, many processes are required and different parts require different processes, but the properties of materials and other things change with the processes. The project is a mission of creating something new, which is the innovative i.e. manufacturing of a new product. The prime requirements of an effective project organization therefore are:

- Flexibility 
- Autonomy

- Group functional integration

- Small group size

- Common work location for all project members

\section{LITERATURE SURVEY}

The history of Pantograph falls far behind in 1603. Christopher Scheiner, (1603). The pantograph was originally invented as a means to trace original art and then scale it up or down in size. "One arm of the pantograph contained a small pointer, while the other held a drawing implement, and by moving the pointer over a diagram, a copy of the diagram was drawn on another piece of paper. By changing the positions of the arms in the linkage between the pointer arms and drawing arm, the scale of the image produced can be changed. Benton Pantograph 1884: American typeface designer Linn Boyd Benton created the Benton Pantograph, an engraving machine capable not only of scaling font design patterns to a variety of sizes, but also condensing, extending and slanting the design. Mathematically, the pantograph works in the affine transformation which is the fundamental geometric operation of most systems of digital typography today, including PostScript. Aesthetically the machine was incapable of replacing the punch cutter's intuitive balancing of line weights, counterpanes ,and proportion as the type was scaled. Beatrice Warde remarked on the invention of the pantograph, "The operator, by the way, is likely to be a young woman, as the work requires a combination of manual dexterity and almost hypnotic concentration, to which any flash of creative, independent thoughts would be a positive handicap. The Huge Impact of the Typographic Pantograph in an interview by Mark Solsburg, Mathew Carter remarked on the repercussions of the pantograph on the typographic community. "A Milwaukee engineer named Linn Boyd Benton put the first 'nail in the coffin' of local foundries in 1884 when he invented a pantographic punch cutter, the router-like engraving machine for cutting the steel punches for a type. That was the most important technical development in typography since Gutenberg's invention of variable-width type molds in the 15th century." "The machine age in the form of the pantograph and mechanical typesetting was beating against the door of hand-work. By the 1920's the whole process of type manufacture had been taken into mass production and carried out under factory conditions.

A great number of publications were found during this literature review that was specifically devoted to Kaizen. This publication generally discussed the overall methodology of kaizen and how to implement kaizen programs. However, the little information was found on the cost and benefits of kaizen at companies. In doing this review, it was evident that this research would be important in contributing studies on this project.

Haverford Township et al, the invention relates to reproducing devices or copying devices and particularly to pantographs. An object of the present invention is to provide pantograph for use with a heavy-duty metal-working or the wood-working machine such as a milling machine.

The objective of the present invention is to provide a pantograph or similar reproducing device. Now measure the center of rotation of rotatable pattern-supporting member moves relative to a tracing point. The distance the center of rotation of a rotatable Work-supporting member moves relative to a duplicating member. [1] K.Zwick, the invention relates to engraving and copying the machine of the type in which a pantograph system is used, a cutting tool and tracing point or stylus being mounted on the pantograph system. An object of the invention is to provide a generally improved and 
more the satisfactory machine of this character, and particularly one in which heavy cutting may be accomplished with little or no exertion on the part of the operator, irrespective of the direction of the cut. [2]

\section{PANTOGRAPH}

The pantograph is a geometrical instrument used in drawing offices for reproducing given geometrical figures or plane areas of any shape, on an enlarged or reduced scale. It is also used for guiding cutting tools. Its mechanism is utilized as an indicator rig for reproducing the displacement of cross-head of a reciprocating engine which, in effect, gives the position of displacement. A pantograph is a simple yet powerful tool which can broaden the scope of artwork and crafting. We can copy images to a reduced or enlarged scale with a pantograph depending on how the parts are measured and assembled. The pantograph does the image resize calculating for us by using the distances between its pivot points as the "algorithm" for creating your finished copy. The pantograph in the illustration would produce a copy of the original. By reversing the positions of the pencil and stylus, we would get a copy smaller than the original. This could be a handy tool if we want to get into painting small wall murals.

\section{PANTOGRAPH MECHANISM}

A pantograph is an instrument used to reproduce an enlarged or a reduced scale and as exactly as possible the path described by a given point. It consists of a jointed parallelogram $\mathrm{ABCD}$ as shown in Figure 1.

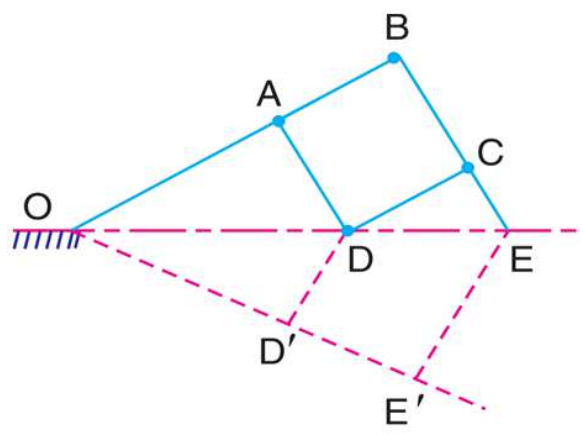

Figure 1: Line Diagram of Pantograph Mechanism

It is made up of bars connected by turning pairs. The bars BA and BC are extended to $\mathrm{O}$ and $\mathrm{E}$ respectively, such that

\section{$\mathrm{OA} / \mathrm{OB}=\mathrm{AD} / \mathrm{BE}$}

Thus, for all relative positions of the bars, the triangles $\mathrm{OAD}$ and $\mathrm{OBE}$ are similar and the points $\mathrm{O}, \mathrm{D}$, and $\mathrm{E}$ are in one straight line. It may be proved that point $\mathrm{E}$ traces out the same path as described by point $\mathrm{D}$.

From similar triangles $\mathrm{OAD}$ and $\mathrm{OBE}$, we find that

\section{$\mathrm{OD} / \mathrm{OE}=\mathrm{AD} / \mathrm{BE}$}

Let point $\mathrm{O}$ be fixed and the points $\mathrm{D}$ and $\mathrm{E}$ move to some new positions $\mathrm{D}^{\prime}$ and $\mathrm{E}^{\prime}$. Then

\section{$\mathrm{OD} / \mathrm{OE}=\mathrm{OD}^{\prime} / \mathrm{OE}^{\prime}$}

A little consideration will show that the straight line $\mathrm{DD}^{\prime}$ is parallel to the straight line $\mathrm{EE}^{\prime}$. Hence, if $\mathrm{O}$ is fixed to the frame of a machine by means of a turning pair and $\mathrm{D}$ is attached to a point in the machine which has rectilinear motion 
relative to the frame, then $\mathrm{E}$ will also trace out a straight line path. Similarly, if $\mathrm{E}$ is constrained to move in a straight line, then D will trace out a straight line parallel to the former.

A pantograph is mostly used for the reproduction of plane areas and figures such as maps, plans etc., on enlarged or reduced scales. It is, sometimes, used as an indicator rig in order on reproduce to a small scale the displacement of the crosshead and therefore of the piston of a reciprocating steam engine. It is also used to guide cutting tools. A modified form of pantograph is used to collect power at the top of an electric locomotive. Line diagram of Pantograph with dimensions is shown in Figure 2.

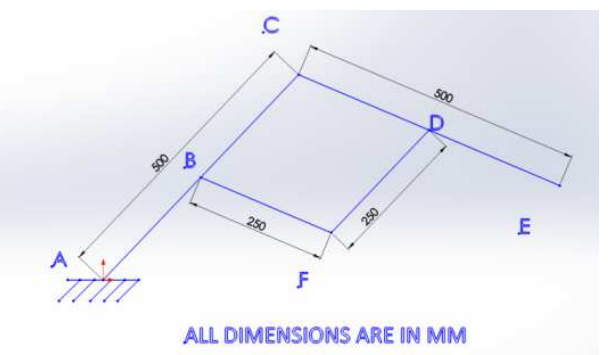

Figure 2: Line Diagram of Pantograph with Dimensions

- In AC bar, 'A' is fixed in all degrees of freedom except in turning or rotating in the z-axis.

- In CE bar, 'E' is pencil point where you can attach a pencil. This helps to draw the required shape.

- In BF or DF, 'F' is tracing point where the tracer is fitted. This helps to trace the lines of the drawing.

- $\quad \mathrm{BF}$ bar is parallel to the CE bar.

- $\quad \mathrm{DF}$ bar is parallel to the $\mathrm{AC}$ bar.

- The A, F, E joints should lie on the same line.

\section{DESIGN CALCULATION}

\section{Design of Bars}

The design of the pantograph is based on the scale ratio. It means the ratio between the scale of the original diagram and the scale of the enlarged or reduced diagram.

The formula used to find the scale ratio is:

Scale ratio $=\frac{\text { scale of the original diagram }}{\text { scale of the enlarged or reduced diagram }}$ or

Scale ratio $=\frac{\text { distancebetweenfixedandtracepoint }}{\text { distancebetweenthefixedandpencilpoint }}$

$\Rightarrow$ Scale ratio $=\frac{A F}{A E} \ldots \ldots \ldots$

In above figure,triangle $\mathrm{ABF}$ is similar to the triangle $\mathrm{ACE}$.

So, the ratios of similar triangles must be constant.

i.e., $\frac{A B}{A C}=\frac{B F}{C E}=\frac{A F}{F E}=$ constant..... 
From the equation (1) \& (2)

$\frac{B F}{C E}=\frac{A F}{F E}$

Substitute equation (3) in (1)

$\Rightarrow$ Scale ratio $=\frac{B F}{C E}$

In this project, Let us consider the length of the $\mathrm{AB}$ bar is $540 \mathrm{~mm}$ because the project is medium size.so, $540 \mathrm{~mm}$ bar is optimum. So, remaining bars also be $540 \mathrm{~mm}$.

Multiple scale ratio can be achieved by selecting the Centre distance between the holes where hinge joint can be created. Let assume initial 50mm center distance between holes. Therefore, we can achieve 9-scale ratio.

They are:

- Scale ratios $=50 / 500=1 / 10=1: 10$

- Scale ratios $=100 / 500=2 / 10=2: 10$

- Scale ratios $=150 / 500=3 / 10=3: 10$

- Scale ratios $=200 / 500=4 / 10=4: 10$

- Scale ratios $=250 / 500=5 / 10=5: 10$

- Scale ratios $=300 / 500=6 / 10=6: 10$

- Scale ratios $=350 / 500=7 / 10=7: 10$

- Scale ratios $=400 / 500=8 / 10=8: 10$

- Scale ratios $=450 / 500=9 / 10=9: 10$

But, the first scale ratio not be considered because in this if input is $1 \mathrm{~mm}$ then it creates $10 \mathrm{~mm}$ same as yo $u$ need more force to move the tracer and by experimentally the accuracy will be very less for this ratio. Then deleted the $1: 10$ ratio.

And then last ratio 9:10 not be considered because the input ratio and output ratio almost be equal so no need of this mechanism. From this two ratios are deleted. Now it has 7 scale ratios. they are:2:10,3:10, 4:10, 5:10,6:10, 7:10\& 8:10. Two-trace bars length is changed from $540 \mathrm{~mm}$ to $440 \mathrm{~mm}$. Four bars length are:540mm, 540mm,440mm, 440mm. The Pantograph Material Properties are shown in Table 1. 
Table 1: Pantograph Material Properties

\begin{tabular}{|c|c|c|c|}
\hline Material: & \multicolumn{3}{|c|}{$\begin{array}{c}\text { Stainless Steel - } \\
\text { Grade } 304 \text { (UNS S30400) }\end{array}$} \\
\hline Composition: & \multicolumn{3}{|c|}{$\begin{array}{c}\mathrm{Fe} /<.08 \mathrm{C} / 17.5-20 \mathrm{Cr} / 8-11 \\
\mathrm{Ni} /<2 \mathrm{Mn} /<1 \mathrm{Si} /<.045 \mathrm{P} /<.03 \mathrm{~S}\end{array}$} \\
\hline Property & $\begin{array}{l}\text { Minimum } \\
\text { Value (S.I.) }\end{array}$ & $\begin{array}{l}\text { Maximum } \\
\text { Value (S.I.) }\end{array}$ & $\begin{array}{l}\text { Units } \\
\text { (S.I.) }\end{array}$ \\
\hline Atomic Volume (average) & 0.0069 & 0.0072 & $\mathrm{~m}^{3} / \mathrm{kmol}$ \\
\hline Density & 7.85 & 8.06 & $\mathrm{Mg} / \mathrm{m}^{3}$ \\
\hline Energy Content & 89 & 108 & $\mathrm{MJ} / \mathrm{kg}$ \\
\hline Bulk Modulus & 134 & 151 & $\mathrm{GPa}$ \\
\hline Compressive Strength & 205 & 310 & $\mathrm{MPa}$ \\
\hline Ductility & 0.3 & 0.57 & $\mathrm{MPa}$ \\
\hline Elastic Limit & 205 & 310 & $\mathrm{MPa}$ \\
\hline Endurance Limit & 175 & 260 & $\mathrm{MPa}$ \\
\hline Hardness & 1700 & 2100 & $\mathrm{MPa}$ \\
\hline Modulus of Rupture & 205 & 310 & $\mathrm{MPa}$ \\
\hline Poisson's Ratio & 0.265 & 0.275 & \\
\hline Shear Modulus & 74 & 81 & $\mathrm{GPa}$ \\
\hline Tensile Strength & 510 & 620 & $\mathrm{MPa}$ \\
\hline Young's Modulus & 190 & 203 & $\mathrm{GPa}$ \\
\hline Latent Heat of Fusion & 260 & 285 & $\mathrm{~kJ} / \mathrm{kg}$ \\
\hline Maximum Service Temperature & 1023 & 1198 & $\mathrm{~K}$ \\
\hline Melting Point & 1673 & 1723 & $\mathrm{~K}$ \\
\hline Minimum Service Temperature & 0 & 0 & $\mathrm{~K}$ \\
\hline Specific Heat & 490 & 530 & $\mathrm{~J} / \mathrm{kg} . \mathrm{K}$ \\
\hline Thermal Conductivity & 14 & 17 & $\mathrm{~W} / \mathrm{m} . \mathrm{K}$ \\
\hline Thermal Expansion & 16 & 18 & $10^{-6} / \mathrm{K}$ \\
\hline Resistivity & 65 & 77 & $10^{-8} \mathrm{ohm} . \mathrm{m}$ \\
\hline
\end{tabular}




\section{Design of Bench Holder}

The shape of the holder is ' $\mathrm{C}$ ' shaped and its dimensions are shown in Figure 3. The width of the plate:50mmThickness of the plate:3mm. It has two holes, one is for hinge joint with the support bar, and another one is for tightening the bolt to fix the holder to bench. BOLTS:For easy hinge joint taking the $6 \mathrm{~mm}$ bolt is optimum.

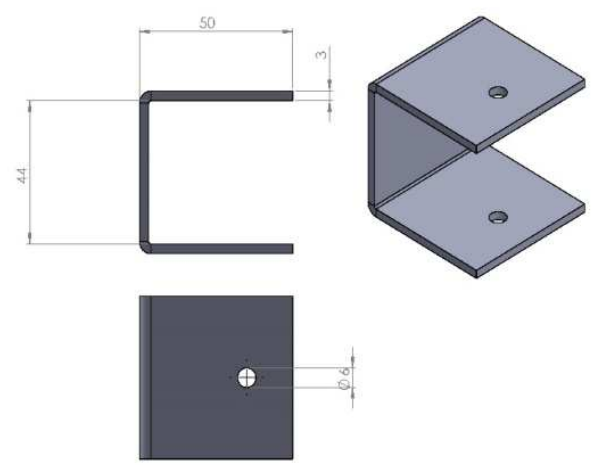

Figure 3: C Shape Bench Holder for Fixing the Pantograph

\section{FABRICATION TECHNIQUES}

Steps involved in the fabrication

\section{Procuring}

- $18 \mathrm{~mm} * 540 \mathrm{~mm} * 5 \mathrm{~mm}$ bars are required but in mark the standard $25.4 \mathrm{~mm} * 540 \mathrm{~mm} * 5 \mathrm{~mm}$ bars are available. so,4$25.4 \mathrm{~mm} * 540 \mathrm{~mm} * 5 \mathrm{~mm}$ are bought.

- A plate with dimensions $50 \mathrm{~mm} * 150 \mathrm{~mm} * 3 \mathrm{~mm}$

- $6 \mathrm{~mm}$ bolt with $25.4 \mathrm{~mm}$ length of 5 pieces for hinge joint.

- $6 \mathrm{~mm}$ bolt with $50.8 \mathrm{~mm}$ length of 1 piece for bench holder.

- $6 \mathrm{~mm}$ hexagonal nut of six numbers.

- $6 \mathrm{~mm}$ washers of six numbers.

- $\quad$ Open head spanner (12-13mm).

\section{Marking}

Mark the points for every $50 \mathrm{~mm}$ on the bars on Centre axis for drilling.

Mark the points on the plate in Centre.

\section{Drilling}

Drill the holes on the marked point with $6 \mathrm{~mm}$ bolt. And also drill the holes on the plate.

\section{Shaping}

Shaping is required to reduce the width of the bar for required shape. 


\section{Cutting}

After shaping the bars, two bars are reduced from $540 \mathrm{~mm}$ to $440 \mathrm{~mm}$ length by cutting (remove two holes). And another bar is reduced from $540 \mathrm{~mm}$ to $470 \mathrm{~mm}$ for (remove one hole) for fabrication of compass bar.

\section{Gas welding}

A bar, which is cut to the $470 \mathrm{~mm}$ bar, should be brazed on one side (one hole removed side) with a compass to hold the pencil for drawing on sheet metal. Compass and bar is different material so, brazing is suited for joining.

\section{Bending}

Bend the plate to $\mathrm{C}$ shape by using hammer and bench wise. For easy bending slightly cut the plate where it bends.

\section{Surface Grinding}

For finishing, the surface of the bars should be ground by hand grinding.

\section{Assembly}

Assemble the parts as shown in the figure.

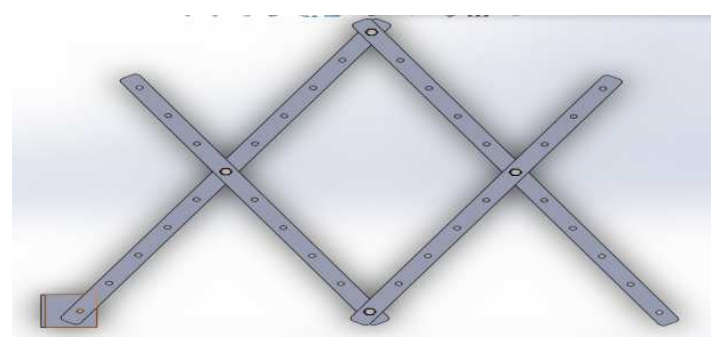

Figure 4: Assembly of Mechanism

- Drawing the lines and shapes of original by enlarging.

- $\quad$ Projecting the shapes on the sheet metal for sheet metal cutting.

- Replacement of the scale, compass, protractor, drafter etc., on the sheet metal work table.

- Seven different enlarged scale ratio.

- $\quad$ Single reference id enough to draw multi times.

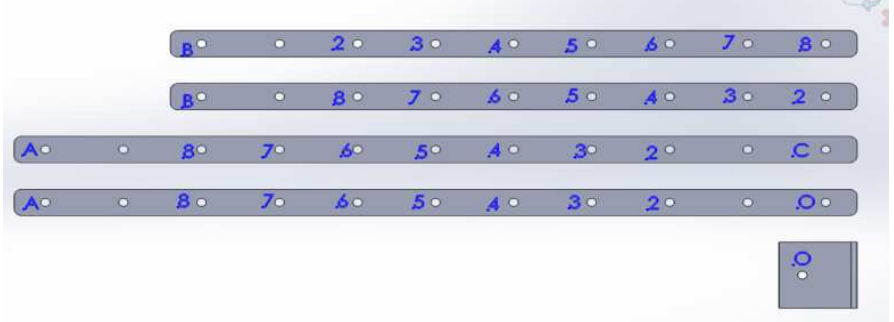

Figure 5: Bars with Scale Ratio Numbers 
Check the list

- 4 bars length $540 \mathrm{~mm}, 540 \mathrm{~mm}, 440 \mathrm{~mm} \& 440 \mathrm{~mm}$

- One bench holder, which is in c shape.

- Six $8 \mathrm{~mm}$ bolts with a $50 \mathrm{~mm}$ length

- $\quad$ Six $8 \mathrm{~mm}$ nuts

- $\quad$ Six 8mm washers

- One open head double head spanner(12-13mm)

- HB pencil which is sharped.

First, the bench holder was fixed to the bench at the bottom left corner tightly by tightening the bolt which is in the bottom of the bench holder. OA bar was fixed with hinge joint with the bench holder by using the bolt and nut at the holes ' $\mathrm{O}$ '. Tightened as much as required by checking free movement. The AC bar and hinge joint were joined with OA by using the bolt and nut at the holes 'A'. First, the scale ratio as mentioned below was selected,2:10, 3:10, 4:10, 5:10 or 1:2,6:10, 7:10\&8:10. This user manual is explained for the scale ratio 6:10. the below steps are similar to the other ratio.

Now, not the 'B2' bar and make hinge joint with the 'B8' bar by using the bolt and nut at the wholes 'B'. Tightened it as much as required by checking free movement. For 6:10 scale ratio, join the whole ' 6 ' on OA bar and the hole ' 6 ' on the B8 bar by using the bolt and nut. Tightened it as much as required by checking free movement.

For 6:10 scale ratio, join the hole ' 6 ' on OA bar and the whole ' 6 ' on the B8 bar by using the bolt and tighten. Tight it as much as required by checking free movement.

Check all the bolts and nuts are tighten and check the bars are moving freely without vibrationFix the pencil at the ' $\mathrm{C}$ ' where the compass or rounder are welded on the side of the AC bar. Now setup or assembly of the pantograph mechanism is completed, here the bolt at ' $\mathrm{B}$ ' hinge joint is used as tracer. Move the tracepoint on the lines, which are on the paper. Put the sheet metal below the point. In addition, the diagram will be drawn atomically with required scale ratio.

\section{CONCLUSIONS}

Pantograph may be an old mechanism, but still, in present days, it has many beneficial uses.

The pantograph is parallelogram linkage, which is used in paper engraving purpose on material like wood.

Our model is having low weight, portable and easy to handle for unskilled persons also than other complicated engraving machines.

We designed such mechanism for engraving machine, which is safe; hence, there are no problems in manufacturing too.

Seven different scale ratio can be achieved in this machine with high accuracy.

\section{REFERENCES}

1. S.K. Saha, Rajendra Prasad and Ananta K. Mandal., "Use of Hoeken's and Pantograph Mechanisms for Carpet Scrapping Operations". 
2. MahendraVarma, Abrar Ahmad, Niyazul S. Haque, Sahil L. Mallick, IshankMehata, "The Mechanism and Kinematics of a Pantograph Milling Machine”, R.K. Tyagi,2013.

3. Theory of machines-R.S. Khurmi.

4. Applications of pantograph International journal of advancements in Mechanical and Aeronautical Engineering VOLUME 1: Issue

5. A Manual for Machine Engravers-By: Charles Harwood Mathews.

6. The Mechanism and Kinematics of a Pantograph Milling Machine Mahendra Verma, Abrar Ahmad, Niyazul S Haque, Sahil L Mallick, Ishank Mehta, R. K. Tyagi-Amity School of Engineering \& Technology, Amity University, Noida, India

7. US Patent number: 4,863,318 PANTOGRAPH MACHINE 4,278,117 7/1981 Mitchell et al. Inventor: Peter M. Pearl, Leucadia, Calif. Assignee: Kathleen M, Hash, Redway, Calif. 